\title{
Effect of root canal preparation, type of endodontic post and mechanical cycling on root fracture strength
}

\author{
Marília Pivetta RIPPE', Manuela Favarin SANTINI², Carlos Alexandre Souza BIER ${ }^{3}$, Paolo BALDISSARA ${ }^{4}$, Luiz Felipe \\ VALANDRO 5
}

1- Prosthodontic Unit, São José dos Campos Dental School, Univ. Estadual Paulista (UNESP), São José dos Campos, SP, Brazil.
2- Endodontic Unit, Faculty of Odontology, Federal University of Rio Grande do Sul, Porto Alegre, RS, Brazil.
3- Endodontic Unit, Department of Stomatology, Faculty of Odontology, Federal University of Santa Maria, Santa Maria, RS, Brazil.
4- Prosthodontic Unit, Department of Biomedical Sciences, Oral Rehabilitation Unit, University of Bologna, Bologna, Italy.
5- Prosthodontic Unit, Department of Restorative Dentistry, Faculty of Odontology, Federal University of Santa Maria, Santa Maria, RS, Brazil.

Corresponding address: Luiz Felipe Valandro - Faculdade de Odontologia - Universidade Federal de Santa Maria - R. Floriano Peixoto, 1184 - Santa Maria - RS - Brazil - 97015-372 - Phone: +55-55-3220-9276 - Fax: +55-55-3220-9272 - e-mail: Ifvalandro@hotmail.com

Submitted: January 11, 2013 - Modification: January 2, 2014 - Accepted: January 29, 2014

\section{ABSTRACT}

\begin{abstract}
O bjective: To evaluate the impact of the type of root canal preparation, intraradicular post and mechanical cycling on the fracture strength of roots. Material and Methods: Eighty human single rooted teeth were divided into 8 groups according to the instruments used for root canal preparation (manual or rotary instruments), the type of intraradicular post (fiber posts- FRC and cast post and core- CPC) and the use of mechanical cycling (MC) as follows: Manual and FRC; Manual, FRC and MC; Manual and CPC; Manual, CPC and MC; Rotary and FRC; Rotary, FRC and MC; Rotary and CPC; Rotary, CPC and MC. The filling was performed by lateral compactation. All root canals were prepared for a post with a $10 \mathrm{~mm}$ length, using the custom \#2 bur of the glass fiber post system. For mechanical cycling, the protocol was applied as follows: an angle of incidence of $45^{\circ}, 37^{\circ} \mathrm{C}, 88 \mathrm{~N}, 4 \mathrm{~Hz}, 2$ million pulses. All groups were submitted to fracture strength test in a $45^{\circ}$ device with $1 \mathrm{~mm} /$ min cross-head speed until failure occurred. Results: The 3-way ANOVA showed that the root canal preparation strategy $(p<0.03)$ and post type $(p<0.0001)$ affected the fracture strength results, while mechanical cycling $(p=0.29)$ did not. Conclusion: The root canal preparation strategy only influenced the root fracture strength when restoring with a fiber post and mechanical cycling, so it does not seem to be an important factor in this scenario.
\end{abstract}

Keywords: Post and core. Root canal preparation. Aging.

\section{INTRODUCTION}

Some studies have shown that root vertical fractures seem to be caused by little defects, such as cracks and craze lines in the root dentin, which can propagate and cause fracture. These cracks are probably caused by iatrogenic injury ${ }^{14}$, inadequate root canal preparation ${ }^{25}$, overloading during lateral condensation of the gutta-percha ${ }^{29}$, inadequate cementation technique and selection of the intraradicular posts ${ }^{23}$, and by root canal preparation and filling 4,8,30,31.

These cracks can become areas of high stress concentration, when forces are applied during the restoration procedures or from occlusal stress due to mastication, progressing to more catastrophic fractures over time ${ }^{25}$.

Endodontic preparation seems to be one of the factors which can generate irregularities in the root canal ${ }^{25}$; thus, it can cause stress concentration in these places. Therefore, the type of root canal preparation, according to the literature ${ }^{15}$, should be taken into account. There is a significant difference between the manual and the rotary techniques in terms of formation of irregularities in the root dentin ${ }^{15}$.

Although the rotary root canal preparation is faster than the manual one, the former can cause 
greater stress concentration ${ }^{9}$ to the root canal since it has more rotations ${ }^{14}$ per minute than the manual type. Some authors ${ }^{9}$ showed that rotary files cause cracks and craze lines in root dentin when analyzed under stereomicroscopy, while manual root canal preparation did not. However, some studies ${ }^{15,22}$ have indicated that rotary files might eliminate deformations of the canal itself, which can result in more circular-shaped canals, allowing more uniform stress distribution ${ }^{28}$. In addition, some studies $^{28}$ have investigated the impact of root canal preparation techniques on root fracture strength, but no differences between the two techniques were found.

It is important to select an adequate intraradicular post to minimize the risk of root fracture. Some studies ${ }^{1,17,20}$ showed that roots restored with posts mechanically compatible with the dentin, such as quartz or fiber posts, suffer more favorable fractures (likely to be restored) when compared with rigid posts (cast post and core, titanium-, and zirconiaprefabricated posts). Finite element analysis studies ${ }^{7,11}$ corroborate these root failure findings, showing that posts with an elastic modulus closer to dentin (fiber posts) promote more homogeneous stress distribution in the root than rigid posts.

To investigate the relation of root canal preparation and the intraradicular post, cyclic mechanical loading can be used to simulate mastication in vitro. Studies have successfully used mechanical cycling $12,16,27$ to predict the clinic behavior of restoring strategies under different conditions. However, in the study of Nishimura, et al. $^{23}$ (2008), the mechanical cycling did not influence the fracture strength of teeth restored with different posts.

The literature seems contradictory in relation to the impact of the root canal preparation on the formation of cracks and root strength. Additionally, there is no scientific evidence regarding the effect of root canal preparation on the fracture strength of the root restored with different intraradicular posts when the teeth are submitted to cyclical mechanical loading.

Therefore, this study aimed to evaluate the impact of the type of root canal preparation, intraradicular post and mechanical cycling on the fracture strength of roots. The research hypotheses were: (1) The type of root canal preparation does not influence the root fracture strength; (2) The roots restored with a cast post and core promote higher fracture strength values than those obtained with FRC; (3) Mechanical cycling does not influence the fracture strength.

\section{MATERIAL AND METHODS}

This study was approved by the Committee of Ethics in Research of the Federal University of Santa Maria and the teeth were donated by the Human Teeth Bank of the Paulista University (UNIP).

\section{Experimental design}

Eighty teeth $(\mathrm{N}=80)$ were allocated into 8 groups using stratified randomization, with a total of five mandibular and maxillary canines and five mandibular pre-molars for each group. All teeth were mesio-distally and bucco-lingually radiographed to eliminate the teeth that presented 2 canals, previous endodontic treatment and with atresia and amplitude too. The teeth with curved root, large caries involving the root and incomplete rizogenesis were also excluded from the study. Care was taken so that only similar roots were selected with similar mesio-distal and buccal-lingual amplitude. The 8 groups were based on 3 factors: root canal preparation strategy (2 levels: manual and rotary), intraradicular post (2 levels: cast post and core and fiber post), and mechanical cycling (2 levels: with and without ), according to Figure 1.

\section{Root canal preparation strategy}

The coronal portion of each tooth was removed with diamond burs in order to obtain roots that were

\begin{tabular}{|c|c|c|c|}
\hline $\begin{array}{c}\text { Root canal preparation } \\
\text { type }\end{array}$ & Post type & MC* & Groups (n=10) \\
\hline Manual & Fiber post & Without & $\mathrm{G} 1$ \\
\hline Manual & Fiber post & With & $\mathrm{G} 2$ \\
\hline Manual & Cast post and core & Without & $\mathrm{G} 3$ \\
\hline Manual & Cast post and core & With & $\mathrm{G} 4$ \\
\hline Rotary & Fiber post & Without & $\mathrm{G} 5$ \\
\hline Rotary & Fiber post & With & $\mathrm{G} 7$ \\
\hline Rotary & Cast post and core & Without & $\mathrm{G} 8$ \\
\hline Rotary & Cast post and core & With & \\
\hline
\end{tabular}

( ${ }^{*} \mathrm{MC}=$ mechanical cycling)

Figure 1- Testing groups 
$15 \mathrm{~mm}$ in length.

Forty teeth were prepared with manual files (Fexile Mani, MANI, Inc., Nakaakutsu, TakanezawaMachi, Japan), by one operator only, using a balanced force crown down technique to file \#35 with $1 \mathrm{~mm}$ step-back increments with \#40 to 60 files, resulting in a preparation with a taper of about 0.05 . The preparation length was $14 \mathrm{~mm}$.

The root canals of the other 40 specimens were prepared with rotary NRT NiTi files (Mani, Mani Inc., Nakaakutsu, Takanezawa-Machi, Japan) using a torque-control motor (Endo Pro Torque, Driller, Jaguaré, SP, Brazil) at the torque (1.4 N.cm) and speed (300 rpm) as recommended by the manufacturer. The \#35 (0.12), \#30 (0.10), and \#25 (0.10) files were used to enlarge the canal opening. The middle and apical thirds were prepared with the following file sequence: 35 (0.06); 35 (0.04); $30(0.06) ; 30(0.04)$ until $15(0.06) ; 15(0.04)$. This sequence was repeated until the 35 file (0.06) achieved the working length, resulting in a preparation with a taper of 0.06 . The irrigation was performed using a disposable syringe and Endo Eze tips (Ultradent, Ultradent Products Inc., Indaiatuba, $\mathrm{SP}$, Brazil) with $2 \mathrm{~mL}$ of $2.5 \%$ sodium hypochlorite $(\mathrm{NaOCl})$ after each instrument change.

After preparation, the cleaning of root canals was performed using a disposable syringe and Endo Eze tips (Ultradent, Ultradent Products Inc., Indaiatuba, $\mathrm{SP}$, Brazil) with $2 \mathrm{~mL}$ of $17 \%$ ethylene diamine tetraacetic acid (EDTA) (Biodinâmica, Biodinâmica Química e Farmacêutica Ltda, Ibiporã, PR, Brazil) for three minutes to remove the smear layer. After the use of EDTA, a final flush using a disposable syringe and Endo Eze tips (Ultradent, Ultradent Products Inc., Indaiatuba, SP, Brazil) with $2 \mathrm{~mL}$ of $2.5 \% \mathrm{NaOCl}$ was performed.

The simulation of the periodontal ligament and root embedding were performed according to Barreto, et al. ${ }^{8}$ (2012).

The obturation was performed using the lateral condensation technique with a controlled force of $3 \mathrm{~kg}$ and the Sealer 26 cement (Dentsply, Dentsply DeTrey, Konstanz, Baden-Württemberg, Germany). This cement (calcium hydroxide-based sealer) takes $12 \mathrm{~h}$ to set and does not interfere in the bond strength of a glass fiber post cemented with self-adhesive resin cements ${ }^{10}$. Twenty-four hours after obturation, each root canal received prosthetic preparation (length of $10 \mathrm{~mm}$ ) with a custom \#2 drill of the glass fiber post system (White Post DC, FGM, Joinville, SC, Brazil).

\section{Type of intraradicular post}

Twenty roots from both root canal preparation methods received glass fiber posts (White Post DC \#2, FGM, Joinville, SC, Brazil) and the other forty received cast post and core.
For the groups using cast posts and cores, the root canals were molded with acrylic resin (DuraLay, Reliance Dental Mfg. Co., Worth, IL, United States) and the core was made from standard silicone matrixes (5 $\mathrm{mm}$ height). The same technician performed all the casting procedures. The cast posts and cores were made of a Ni-Cr alloy (Wironia Light, Bego, Bremen, Bremen, Germany) with the same size and shape of the fiber post.

All the intraradicular posts were cemented with self-adhesive resin cement (RelyX U100, 3M ESPE, St. Paul, MN, USA). The two pastes of the cement were measured and mixed. The cement was applied into the root canal with a \#40 lentulo drill. Each specimen was light-cured for $40 \mathrm{~s}$ (Radii-cal, SDI Brasil Indústria e Comércio Ltda., São Paulo, SP, Brazil) through the incisal side.

For the teeth restored with fiber posts, the coronal dentin received an etch \& rinse single bottle adhesive system (Single Bond 3M, ESPE, St. Paul, MN, USA). The dentin was etched with $37 \%$ phosphoric acid, rinsed with water for $5 \mathrm{~s}$ and dried with absorbent papers. The adhesive agent was then applied per the manufacturer's instructions and light-cured for $20 \mathrm{~s}$ (Radii-cal, SDI Brasil Indústria e Comércio Ltda., São Paulo, SP, Brazil). The core was built up around the $5 \mathrm{~mm}$ of the post left outside the dental root with a composite resin (Filtek $^{\mathrm{TM}}$ Z350 Universal Restorative, 3M ESPE, St. Paul, MN, USA), using the same silicone matrixes used for the cast post and core build-ups, leaving out of the root. The specimens were stored in water $\left(37^{\circ} \mathrm{C}\right)$ for 24 hours.

\section{Mechanical cycling}

For mechanical cycling (MC), specimens were placed in a metallic base at a $45^{\circ}$ angle (immersed in water at $37^{\circ} \mathrm{C} \pm 1^{\circ} \mathrm{C}$ ), and 2 million pulses were induced with a load of $88 \mathrm{~N}$ in the lingual face at a frequency of $4 \mathrm{~Hz}$ (ERIOS 11000 fatigue machine, Erios, São Paulo, SP, Brazil) through a point with a $2.5 \mathrm{~mm}$ diameter tip from the cycling machine $e^{6,10,12,23}$. Specimens not submitted to fatigue testing were stored in distilled water at $37^{\circ} \mathrm{C}$ for the same time period as those that received mechanical cycling.

\section{Fracture resistance test}

Each specimen was positioned in a mounting device and aligned at a $45^{\circ}$ angle with respect to the long axis of the tooth. A universal testing machine (DL-1000, Emic, São José dos Pinhais, PR, Brazil) was used to apply a constant load at a crosshead speed of $1 \mathrm{~mm} / \mathrm{min}$ until failure occurred with a point similar to the cycling machine.

Type of fracture analysis

The type of fracture was classified as: (F1) 
core fracture; (F2) radicular fracture up to or above the simulated bone level; (F3) radicular fracture up to $1 \mathrm{~mm}$ below the simulated bone level; and (F4) radicular fracture more than 1 $\mathrm{mm}$ below the simulated bone level. "F1" and "F2" were considered reparable failures, whereas "F3" and "F4", irreparable failures. The failure analysis was performed using a stereoscopic loupe at a magnification of 4x (EyeMag Pro S, 4x, Carl Zeiss do Brasil Ltda., São Paulo, SP, Brazil) and transillumination.

\section{Qualitative morphologic analysis of the intracanal dentin}

Four additional roots were prepared, two using manual files and two using rotary files. These roots were observed under stereomicroscope at a magnification of $15 x$ (Stereo Discovery V20, Carl Zeiss do Brasil Ltda., São Paulo, SP, Brazil) to analyze the morphology of the canal into the cervical third, and to compare the roots before and after root canal preparation with each file. After this analysis, the roots were cut in a low speed diamond saw (Labcut 1010, Extec Corp, Enfield, CT, USA) in a longitudinal direction and analyzed by scanning electron microscopy (JSM-6360 SEM, JEOL Ltd., Peabody, MA, United States) at a magnification of $43 x$.

The other 2 root canals were prepared with two different endodontic instrument types and prepared using the custom drill of the fiber post system. They were analyzed under stereomicroscopy at a magnification of $15 x$. After this analysis, the roots were cut in a low speed diamond saw (Labcut 1010, Extec Corp, Enfield, CT, USA) in a longitudinal direction and analyzed by scanning electronic microscopy (JSM-6360 SEM, JEOL Ltd., Peabody, MA, United States) in the cervical and median thirds at a magnification of 30x and 50x, respectively.

\section{Statistical analysis}

The fracture resistance data was compared

Table 1- Means (and standard deviation) of the results of the fracture resistance $(\mathrm{N})$ for different groups

\begin{tabular}{ccccc}
\hline Instrumentation & Without MC & Without MC2 & With MC & With MC2 \\
& Fiber Post & Metallic Post & Fiber Post & Metallic Post \\
\hline Manual file & G1- $510(199.8)^{\mathrm{A}, \mathrm{a}}$ & $\mathrm{G} 3-707.5(125.6)^{\mathrm{A}, \mathrm{b}}$ & $\mathrm{G} 2-389.9(136)^{\mathrm{B}, \mathrm{a}}$ & $\mathrm{G} 4-730.1(166.1)^{\mathrm{A}, \mathrm{b}}$ \\
Rotary file & $\mathrm{G} 5-554.9(131.2)^{\mathrm{A}, \mathrm{a}}$ & $\mathrm{G} 7-850.7(343.3)^{\mathrm{A}, \mathrm{b}}$ & G6- 555.7 (201) $)^{\mathrm{A}, \mathrm{a}}$ & G8- 757.4 (204.5) $)^{\mathrm{A}, \mathrm{b}}$ \\
\hline
\end{tabular}

MC: Mechanical cycling

The different small letters indicate a significant difference $(p<0.05)$ between the post types maintaining the same file type and cycling. Different capital letters indicate a significant difference $(p<0.05)$ between file types maintaining the same post type and cycling

Table 2- Failure types numbers by $t$ test between the post types maintaining the same endodontic file and mechanical cycling

\begin{tabular}{ccccc}
\hline Groups & Reparable & Reparable & Irreparable & \multicolumn{2}{c}{ Irreparable } \\
\hline Man, FRCb & F1 & F2 & F3 & F4 \\
\hline Man, CPCa & 8 & 1 & 2 & - \\
Man, FRC, MCb & - & 3 & 1 & 5 \\
Man, CPC, MCa & 4 & 5 & 6 & - \\
Rot, FRCb & - & 3 & 1 & 1 \\
Rot, CPCa & 5 & 4 & 1 & - \\
Rot, FRC, MCb & - & 4 & - & - \\
\hline Rot, CPC, MCa & 4 & 6 & 1 & 3 \\
\hline
\end{tabular}

Captions: Man - Manual root canal preparation; FRC - Glass fiber post; MC - Mechanical cycling; Rot - Rotary root canal preparation; CPC - Cast post and core.

${ }^{*}$ Different small letters indicate a significant difference in the types of failure $(p<0.05)$

${ }^{* *} \mathrm{~F} 1$ : core fracture

F2: root fracture up to the simulated bone level

F3: root fracture up to $1 \mathrm{~mm}$ below the simulated bone level

F4: root fracture more than $1 \mathrm{~mm}$ below the simulated bone level 
using the 3-way Analysis of Variance (root canal preparation, post, cycling) and later by the post hoc Student $T$ test $(p<0.05)$ for pair comparisons. The failure types observed were classified by descriptive statistics in the SPSS program.

\section{RESULTS}

The statistical analysis showed that the root canal preparation strategy $(p<0.03)$ and post type $(p<0.0001)$ affected the fracture strength results,

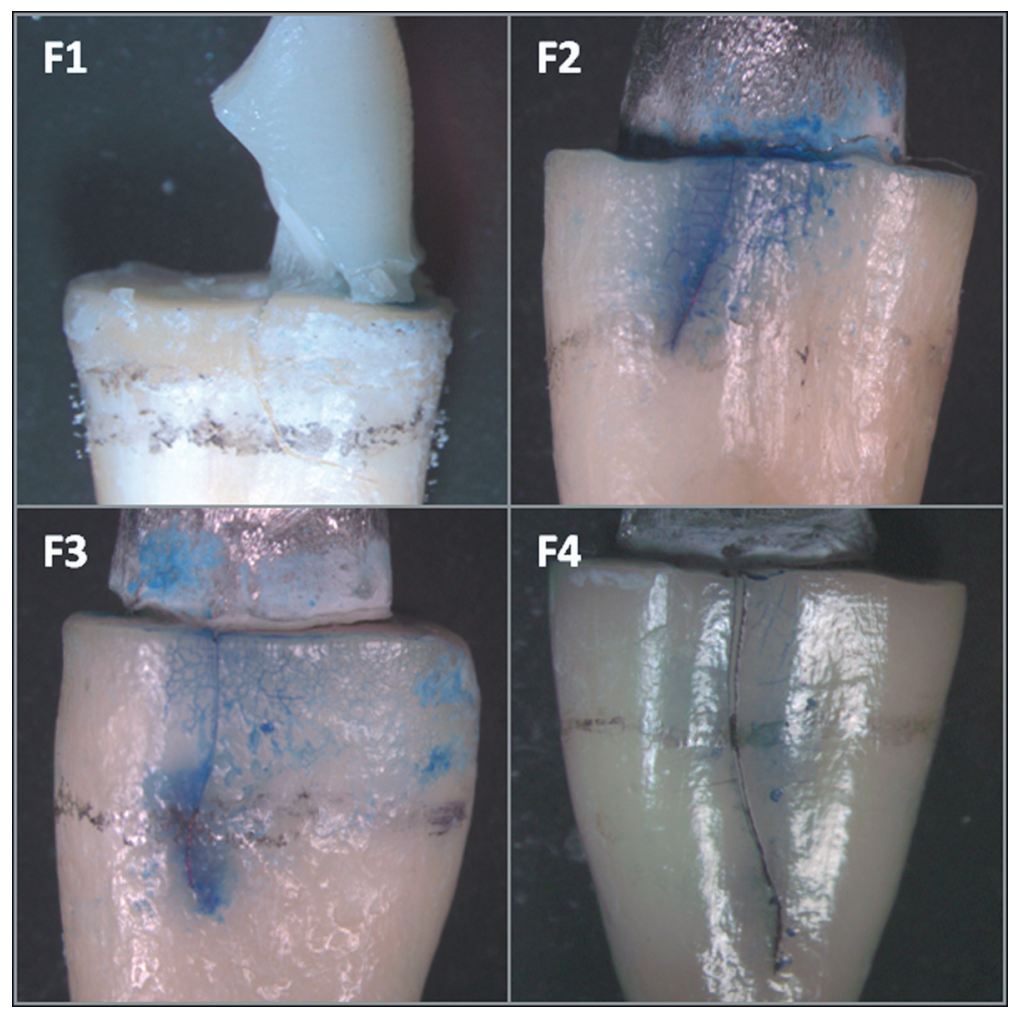

Figure 2- Photographs from stereomicroscopy of the failure types. F1) core fracture; F2) root fracture up to the simulated bone level; F3) root fracture up to $1 \mathrm{~mm}$ below the simulated bone level; F4) root fracture more than $1 \mathrm{~mm}$ below simulated bone level

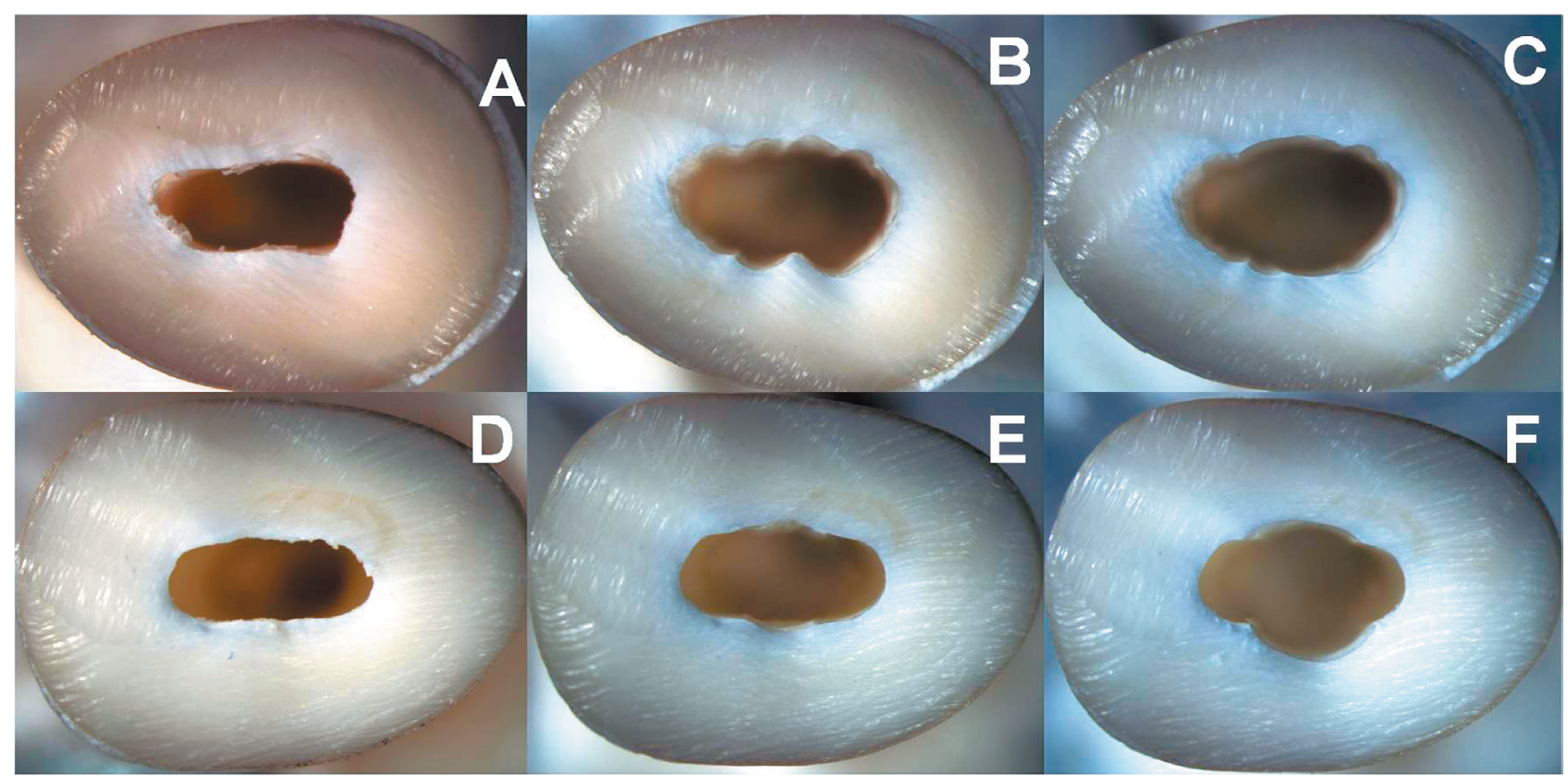

Figure 3- Photographs from stereomicroscopy (magnification 15x) of the root cervical third. Root canal before (A) and after (B) manual preparation; canal after prosthetic preparation (C). Root canal before (D) and after (E) rotary preparation; canal after prosthetic preparation $(F)$ 


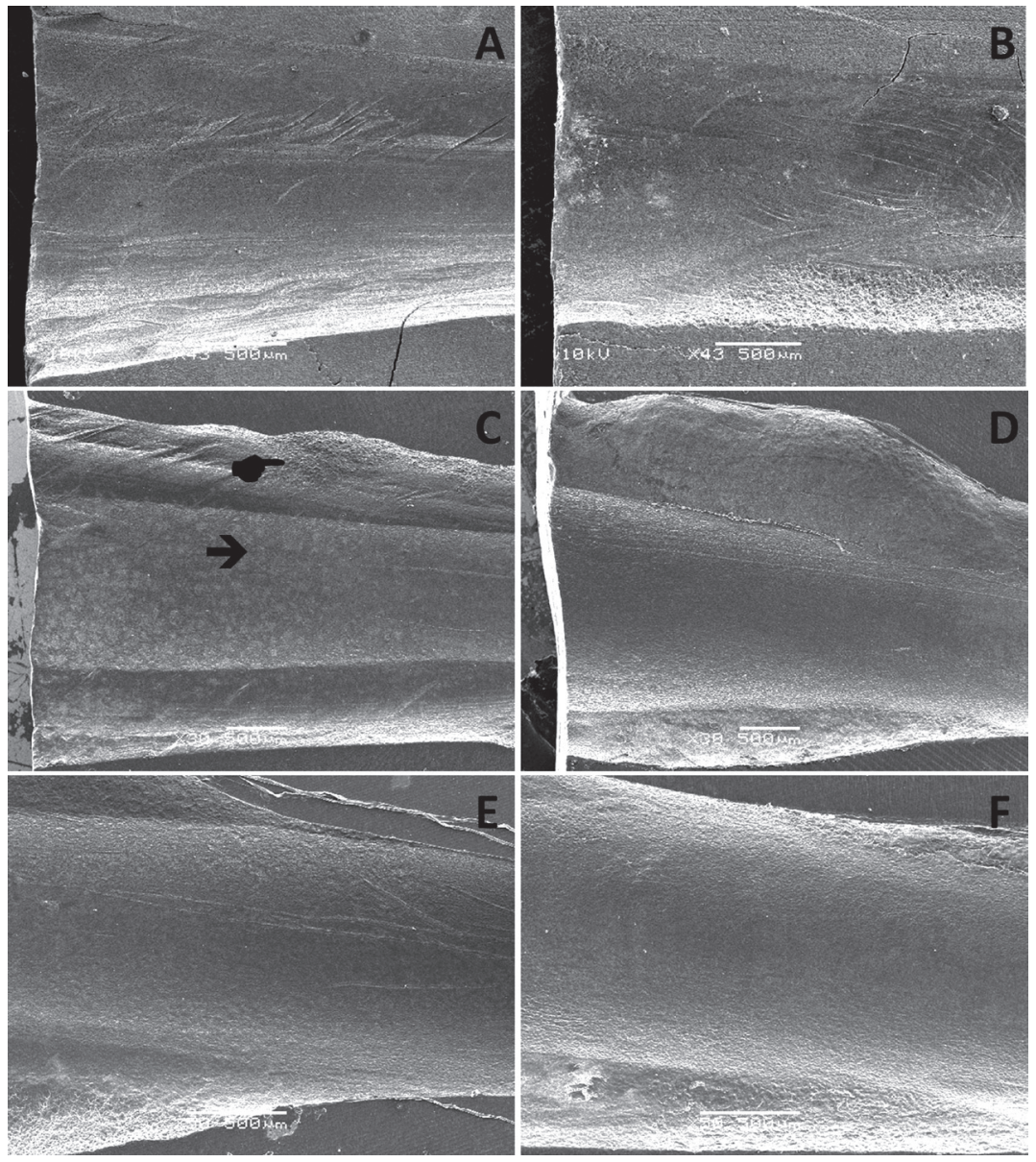

Figure 4- Photomicrographs of root dentin surface: A) canal prepared with manual files (43x); B) canal prepared with rotary files (43x); C) canal after manual and prosthetic preparation, cervical third (30x); D) canal after rotary and prosthetic preparation, cervical third (30x); E) canal after manual and prosthetic preparation, middle third (50x); F) canal after rotary and prosthetic preparation, middle third $(50 \mathrm{x})$. The indicator $(-)$ shows the root region prepared with manual file; the indicator $(\rightarrow)$ shows the root region where the post space bur wore the dentine and eliminated the irregularities caused by manual files

while mechanical cycling $(p=0.29)$ did not (Table 1$)$. Moreover, regarding failure pattern, the post type $(p<0.0001)$ was statistically significant, although the mechanical cycling $(p=0.643)$ and the root canal preparation $(p=0.643)$ factors were not significant (Table 2).

Figure 2 shows that most of the failures were reparable in groups restored with glass fiber post. Irreparable failures were predominant in groups restored with cast post and core. Figure 3 also shows the stereomicroscopy images of the cervical third before and after root canal preparation with the manual and rotary techniques and after post space.

The photomicrographs (Figure 4) show the cervical third after root canal preparation with a manual file " $4 A$ " and with rotary files " $4 B$ ". The manual files seem to cause more frequent irregularities and wider preparations than the rotary files. Rotary root canal preparation seems to generate a preparation that is more regular and narrow, which indicates less wear of the intraradicular dentin. In " $4 \mathrm{C}$ " and " $4 \mathrm{E}$ ", the root canal preparation was performed with manual files and prepared for a post space in the cervical and middle thirds, respectively. These photomicrographs show that the post space preparation did not eliminate (indicator $\rightarrow$ ) the irregularities caused by files (indicator - ), mainly in the middle third, when compared with the rotary files in "4D" and "4F".

\section{DISCUSSION}

Regarding the impact of canal preparation in the different conditions studied (Table 1), only the specimens which received a fiber post and were submitted to mechanical cycling ( $\mathrm{G} 2<\mathrm{G} 6)$ presented a significant influence for the type of root canal preparation. Therefore, the first hypothesis was partially accepted, since the root canal preparation had a specific influence on the conditions of this study.

This statistical difference between the root canal preparation types may have occurred due 
to mechanical cycling over the restoration (post and crown), and not because of the root canal preparation types per se. Furthermore, if the difference had occurred due to the post type, it would also have occurred between G1 and G5. Therefore, it seems that the stress concentration areas promoted by mechanical cycling at the cervical third of roots restored with FRC seem to be the main factor that explains this result.

Manual root canal preparation seems to have induced more frequent irregularities and wear in the cervical dentin than did the rotary root canal preparation. The prosthetic preparation does not seem to eliminate the irregularities caused by the manual and rotary files.

According to Coelho, et al. ${ }^{11}$ (2009), the use of fiber post resulted in higher stress concentration at the facial surface of cervical and middle third dentin regions. This stress location, characteristic of the fiber post, seems to have influenced the type of failure, since the most frequent failure in the restored teeth with this type of post were core fracture and root fracture up to the bone crest. On the other hand, the metallic post, which is more rigid, causing less deformation of the dentin, leads to higher stress concentration in the post and the root apical third ${ }^{11}$, supposedly preventing the effect of the manual files.

In relation to the type of post, groups with metallic posts had higher values of fracture strength, which is in agreement with some studies $^{2,19,20}$. Therefore, the second hypothesis was accepted. This behavior is due to the fact that the cast post and core presented high elastic modulus and homogenous form, which resulted in lower bending of the post-core assembly during the load application $^{16}$. Alternatively, the roots restored with fiber posts, when submitted to a load, tended to fracture before the root, since this type of post has an elastic modulus similar to the dentin and has a longitudinal fiber arrangement ${ }^{20}$.

Regarding the failure analysis, it was influenced only by the type of post (Table 2 ). The main types of failure in the teeth restored with a fiber post were reparable. This behavior is in agreement with Meira, et al. ${ }^{21}$ (2009), who showed that a post with low elastic modulus, when under $45^{\circ}$ oblique load, tends to bend with a fulcrum localized in the cervical third, opposite the load application ${ }^{5}$. Due to the post's low rigidity, the curvature is noticeable, which leads to larger post elongation at the side of the load application. When the post and the dentin are perfectly bonded, a higher post deformation causes greater dentin deformation and, consequently, more stress. Hence, according to the stress concentration and its direction, a trend is found for post debonding, instead of irreparable root vertical fracture ${ }^{21}$. On the other hand, catastrophic failures were evidenced only in the groups which received a cast post and core, since the higher stress concentration occurs in the post and root apical third ${ }^{11}$.

Concerning the mechanical cycling factor, the current study found that this aging did not influence the root fracture strength, since the results of cycling and non-cycling groups were not statistically different, when the same root canal preparation strategy and type of post were considered (Table 1 ). Thus, the third hypothesis of this study was accepted.

The photomicrographs (Figure 4) show the intraradicular dentin of the cervical third after root canal preparation with a manual file in " $\mathrm{A}$ " and with rotary files in "B".

Some studies ${ }^{19,20}$ evaluated the root fracture strength when specimens were restored with a cast post and core and fiber post, and also found no significant difference between the specimens with or without mechanical cycling $(100,000$ cycles, 80 $\mathrm{N})$. These authors also found that the roots restored with a cast post and core presented higher fracture strength, without considering the cyclic loading, corroborating the present study.

Some authors ${ }^{18}$ recommended that the fatigue load must be at least $60 \%$ of the material's monotonic fracture load. Thus, considering the results displayed by the current study, the load to be applied during mechanical cycling should range between $510 \mathrm{~N}$ and $234 \mathrm{~N}$. Alternatively, the maximum masticatory force in canines and premolars in healthy men is about $190 \mathrm{~N}$ and 254 $\mathrm{N}$, respectively, and, in women, $119 \mathrm{~N}$ and $178 \mathrm{~N}$, respectively ${ }^{13}$. Therefore, this study shows that 510 $\mathrm{N}$ and $234 \mathrm{~N}$ exceed the load limit of the maximum bite force of humans by a great amount, mainly in women, which does not seem adequate for aging.

These findings showed that there is controversy in the literature and there is a difficulty in achieving a consensus for establishing the load magnitude to be used in in vitro fatigue tests. Nevertheless, it is emphasized that the aim of mechanical cycling in the present study was only for specimen aging, hence a load of $88 \mathrm{~N}$ was chosen, which approximate the human mastication. However, this fatigue stress was probably not sufficient to propagate cracks or defects which have been generated by root canal preparation, filling and prosthetic preparation to affect the root fracture strength and generate complete fractures during cycling. Not only the number of cycles but also the applied load should be reviewed for future studies with the approach discussed in the present investigation.

Mechanical loading was applied directly onto the core, since no crown was used in accordance with previous studies, for simplification purposes ${ }^{3}$ and to simulate the worst scenario, without effect 
ferrule and without crown. However, the use of complete crowns had a significant influence on stress distribution in endodontically treated teeth ${ }^{26}$ and the no use of the crown might have affected the stress distribution within the tooth and thus the magnitude of fracture loads and the fracture modes of the specimens ${ }^{2}$.

According to the design of this in vitro study, root canal preparation seems to have no influence on the single-root fracture strength. This can be inferred because the statistically significant groups, G2 and G6, are equal to the groups G1 and G5, concerning the root canal preparation and the post types, the only difference between them being the mechanical cycling. Based on this, it can be deduced that the statistical difference of the root canal preparation type in G2 and G6 may have occurred due to the inclusion of mechanical cycling in these groups. Actually, the root canal preparation technique has its influence on the worst results of $\mathrm{G} 2$. When manual root canal preparation was performed, more irregularities were formed at cervical portion, and fiber posts presented more stress concentration at cervical portion. Thus, both the behavior of fiber posts and the irregularities caused by manual root canal preparation have influence on the results. Thus, the post type seems to have a relevant effect in terms of the strength and the type of failure. The cast post and cores, even when prepared with the same diameter of the fiber post and cemented with the same agent cement, provide higher values of resistance, but the roots experimented catastrophic fractures. It should be noted that these catastrophic fractures only occurred under load values higher than physiologic values of force. This might perhaps mean that these fractures could not occur under physiologic loads; consequently, this restoring strategy could have an appropriate clinical performance.

\section{CONCLUSION}

In the experimental conditions applied for this study, it can be concluded that:

- The type of endodontic instrument only influenced the root fracture strength when restoring with a fiber post and mechanical cycling;

- The cast post and core presented the highest fracture resistance values when compared with the fiber posts;

- Mechanical cycling did not influence the fracture resistance or the type of failure.

\section{REFERENCES}

1- Akkayan B, Gülmez T. Resistance to fracture of endodontically treated teeth restored with different post systems. J Prosthet Dent. 2002;87:431-7.

2- Al-Omiri MK, Al-Wahadni AM. An ex vivo study of the effects of retained coronal dentine on the strength of teeth restored with composite core and different post and core systems. Int Endod J. 2006;39:890-9.

3- Al-Wahadni A, Gutteridge DL. An in vitro investigation into the effects of retained coronal dentine on the strength of a tooth restored with a cemented post and partial core restoration. Int Endod J. 2002;35:913-8.

4- Ashraf H, Momeni G, Moradi Majd N, Homayouni H. Fracture resistance of root canals obtured with gutta-percha versus resilon with two different techniques. Iran Endod J. 2013;8:136-9.

5- Baldissara P, Özcan M, Melilli D, Valandro LF. Effect of cyclic loading on fracture strength and microleakage of a quartz fiber dowel with different adhesive, cement and resin core material combinations. Minerva Stomatol. 2010;59:407-14.

6- Baldissara P, Zicari F, Valandro LF, Scotti R. Effect of root canal treatments on quartz fiber posts bonding root dentin. J Endod. 2006;32:985-8.

7- Barjau-Escribano A, Sancho-Bru JL, Forner-Navarro L, Rodríguez-Cervantes PJ, Pérez-González A, Sánchez-Marín FT. Influence of prefabricated post material on restored teeth: fracture strength and stress distribution. Oper Dent. 2006;31:47-54.

8- Barreto MS, Moraes RA, Rosa RA, Moreira CH, Só MV, Bier $C A$. Vertical root fractures and dentin defects: effects of root canal preparation, filling, and mechanical cycling. J Endod. 2012;38:1135-9.

9- Bier CA, Shemesh H, Tanomaru-Filho M, Wesselink PR, Wu MK. The ability of different nickel-titanium rotary instruments to induce dentinal damage during canal preparation. J Endod. 2009;35:236-8.

10- Cecchin D, Farina AP, Souza MA, Carlini-Júnior B, Ferraz CC. Effect of root canal sealers on bond strength of fibreglass posts cemented with self-adhesive resin cements. Int Endod J. 2011;44:314-20.

11- Coelho CS, Biffi JC, Silva GR, Abrahão A, Campos RE, Soares $\mathrm{CJ}$. Finite element analysis of weakened roots restored with composite resin and posts. Dent Mater J. 2009;28:671-8.

12- Dietschi D, Ardu S, Rossier-Gerber A, Krejci I. Adaptation of adhesive post and cores to dentin after in vitro occlusal loading: evaluation of post material influence. J Adhes Dent. 2006;8:40919.

13- Ferrario VF, Sforza C, Serrao G, Dellavia C, Tartaglia GM. Single tooth bite forces in healthy young adults. J Oral Rehabil. 2004;31:18-22.

14- Fuss Z, Lustig J, Katz A, Tamse A. An evaluation of endodontically treated vertical root fractured teeth: impact of operative procedures. J Endod. 2001;27:46-8.

15- Glosson CR, Haller RH, Dove SB, del Rio CE. A comparison of root canal preparations using $\mathrm{Ni}-\mathrm{Ti}$ hand, $\mathrm{Ni}-\mathrm{Ti}$ engine-driven, and K-Flex endodontic instruments. J Endod. 1995;21:146-51.

16- Heydecke G, Butz F, Hussein A, Strub JR. Fracture strength after dynamic loading of endodontically treated teeth restored with different post-and-core systems. J Prosthet Dent. 2002;87:43845.

17- Maccari PC, Cosme DC, Oshima HM, Burnett LH Jr, Shinkai RS. Fracture strength of endodontically treated teeth with flared root canals and restored with different post systems. J Esthet Restor Dent. 2007;19:30-6.

18- Mair L, Padipatvuthikul P. Variables related to materials and preparing for bond strength testing irrespective of the test protocol. Dent Mater. 2010;26:e17-23.

19- Marchi GM, Mitsui FH, Cavalcanti AN. Effect of remaining dentine structure and thermal-mechanical aging on the fracture resistance of bovine roots with different post and core systems. Int Endod J. 2008;41:969-76. 
20- Martínez-Insua A, Silva L, Rilo B, Santana U. Comparison of the fracture resistances of pulpless teeth restored with a cast post and core or carbon-fiber post with a composite core. J Prosthet Dent. 1998;80:527-32.

21- Meira JB, Espósito CO, Quitero MF, Poiate IA, Pfeifer CS, Tanaka $C B$, et al. Elastic modulus of posts and the risk of root fracture. Dent Traumatol. 2009;25:394-8.

22- Moore J, Fitz-Walter P, Parashos P. A micro-computed tomographic evaluation of apical root canal preparation using three instrumentation techniques. Inter Endod J. 2009;42:1057-64.

23- Nishimura $Y$, Tsubota $Y$, Fukushima S. Influence of cyclic loading on fiber post and composite resin core. Dent Mater. 2008;27:356-61.

24- Obermayr G, Walton RE, Leary JM, Krell KV. Vertical root fracture and relative deformation during obturation and post cementation. J Prosthet Dent. 1991;66:181-7.

25- Onnink PA, Davis RD, Blake EW. An in vitro comparison of incomplete root fractures associated with three obturation techniques. J Endod. 1994;20:32-7.
26- Pierrisnard L, Bohin F, Renault P, Barquins M. Corono-radicular reconstruction of pulpless teeth: a mechanical study using finite element analysis. J Prosthet Dent. 2002;88:442-8.

27- Rosentritt M, Fürer C, Behr M, Lang R, Handel G. Comparison of in vitro fracture strength of metallic and tooth-coloured posts and cores. J Oral Rehabil. 2000;27:595-601.

28- Sathorn C, Palamara JEA, Messer HH. A comparison of the effects of two canal preparation techniques on root fracture susceptibility and fracture pattern. J Endod. 2005;31:283-7.

29- Saw LH, Messer HH. Root strains associated with different obturation techniques. J Endod. 1995;21:314-20.

30- Shemesh H, van Soest G, Wu MK, Wesselink PR. Diagnosis of vertical root fractures with optical coherence tomography. J Endod. 2008;34:739-42.

31- Touré B, Faye B, Kane AW, Lo CM, Niang B, Boucher Y. Analysis of reasons for extraction of endodontically treated teeth: a prospective study. J Endod. 2011;37:1512-5. 